\title{
Pre-diapause mating and overwintering of fertilized adult females: New aspects of the life cycle of the wing-polymorphic bug Pyrrhocoris apterus (Heteroptera: Pyrrhocoridae)
}

\author{
RADOMÍR SOCHA \\ Biology Centre ASCR, Institute of Entomology, Branišovská 31, CZ-370 05 České Budějovice, Czech Republic; \\ e-mail: socha@entu.cas.cz
}

Key words. Pre-diapause mating, fertilized females, overwintering, wing polymorphism, life cycle, firebug, Pyrrhocoris apterus

\begin{abstract}
New aspects of the life-cycle of the flightless wing-polymorphic bug Pyrrhocoris apterus (L.) are described. It was found that $1.1-14.9 \%$ of the adult females of P. apterus in 11 samples collected from 4 populations in the South Bohemia had mated prior to entering diapause and their ovaries were in the pre-vitellogenic stage of development with viable sperm in their spermathecae. Some of these females successfully overwintered. The percentage of overwintering females that had been fertilized ranged from 1.1 to $7.2 \%$ and depended on the month and year of collection. The results indicate that pre-diapause mating and overwintering of fertilized females is not unusual in populations of $P$. apterus in the Czech Republic and and that sperm in overwintering female survives for at least 7-8 months.
\end{abstract}

\section{INTRODUCTION}

The firebug, Pyrrhocoris apterus (L.), has been studied as a convenient experimental tool for biological research (for review see Socha, 1993). It is a common palaearctic species particularly in the Mediterranean area and eastern and central Asia. In central Europe, the bug lives at the foot of lime trees (Tilia cordata Miller, T. platyphyllos Scopoli) and feeds on the seeds of these trees. The bug shows a conspicuous wing polymorphism, producing short-winged (brachypterous) and long-winged (macropterous) morphs (Honěk, 1974; Socha, 1993). Both the macropterous and brachypterous adults of $P$. apterus are flightless (Socha \& Zemek, 2000a), disperse by walking (Socha \& Zemek 2000b), with the macropterous adults showing a higher dispersal (Socha \& Zemek, 2003) and lower mating activity than brachypterous adults (Socha 2004, 2006). Development leading to either brachypterous or macropterous morphs is genetically determined (Honěk, 1986a), but influenced by environmental variables (Honěk, 1974, 1976). Under short-day conditions (photophase $<16 \mathrm{~h}$ ), bugs from populations collected in the Czech Republic go into reproductive diapause and virtually all are brachypterous, while under longer days they do not enter diapause and a fraction of each population $(0-14 \%$ and $33 \%$ in the the Czech Republic and Israel, respectively) are macropterous (Honěk, 1976, 1981; Socha, 2001). However, the percentage of macropters varies in natural populations, both between localities and at one locality during a season and may exceed $60 \%$ at some warmer places during hot summers (Honěk, 1986b).

Wing polymorphism and reproductive diapause in $P$. apterus are controlled by photoperiod and temperature, and the photoperiodic control of these traits is geographically dependent (Socha, 1993, 2001). In Czech popula- tions diapause prevents reproductive activity of both sexes in late summer and early autumn (Hodek, 1971) and diapause development is almost complete by December/January (Hodek, 1988). After termination of diapause the bugs begin to copulate and lay eggs even under short-day conditions, which previously induced diapause and inhibited ovarian development. The bugs overwinter as adults, begin copulating in March and laying eggs in March or May (Hodek, 1971; Honěk, 1976), depending on the temperature. The first adults of the new generation appear from the middle or end of June (Socha \& Šula, 1996; Košt’ál \& Šimek, 2000). High temperatures increase the percentage of macropters in late June to early August. Persistence of non-functional macroptery in this species is conjectured to be related to the prevention of immediate oviposition by the macropterous females that moult early and the production of a second generation, which would otherwise be prevented by the approaching end of the season (Honěk, 1987). Reproductive diapause in $P$. apterus is facultative and all individuals are potentially polyvoltine (Hodek, 1968). Voltinism under natural conditions depends on temperature and may indicate climatic changes.

According to many authors, e.g. Schulze (1913), Schwoerbel (1956), Tischler (1959), Pouvreau (1963) and Hodek (1971), P. apterus does not mature eggs in the same year as it becomes adult, but enters directly into diapause. Pre-diapause mating, entry of females into hibernal diapause as fertilized adults and overwintering of fertilized females either were not considered possible or not reported for this species. Pre-diapause mating means mating of females before the onset of reproductive diapause, i.e. either during reproductive activity or the prediapause phase of adult life. This aspect of the life cycle 
TABLE 1. The percentage of diapausing fertilized brachypterous and macropterous females collected from different field populations of $P$. apterus and the average lengths of their pre-oviposition periods (years 2000-2005).

\begin{tabular}{lccc}
\hline Population & $\begin{array}{c}\text { Date of collection } \\
\text { Month and day (Year) }\end{array}$ & $\begin{array}{c}\text { Percentage (\%) of diapausing fertilized females } \\
\text { No. of females tested (n) }\end{array}$ & $\begin{array}{c}\text { Length of pre-OP } \\
\text { (days) } \pm \text { S.D. }\end{array}$ \\
\hline Č. Budějovice & August 2 (2000) & $5.56(18)$ & $22.11 \pm 16.06$ \\
Č. Budějovice & August 23 (2000) & $2.0(50)$ & $24.80 \pm 8.36$ \\
Č. Budějovice & August 10 (2005) & $11.49(87)$ & $24.48 \pm 9.11$ \\
Č. Budějovice & September 13 (2000) & $2.33(50)$ & $33.33 \pm 7.61$ \\
Chelčice & September 20 (2000) & $1.82(81)$ & $31.90 \pm 7.40$ \\
Č. Budějovice & September 14 (2005) & $4.11(73)$ & $25.47 \pm 4.39$ \\
Č. Budějovice & October 18 (2000) & $2.50(40)$ & $28.10 \pm 10.96$ \\
Jistebnice & October 27 (2000) & $14.9(7 *)$ & $26.67 \pm 4.73$ \\
Křemže & October 10 (2001) & $2.35(85)$ & $27.50 \pm 5.13$ \\
Č. Budějovice & November 22 (2000) & $9.10(44)$ & $19.43 \pm 7.93$ \\
Č. Budějovice & November 8 (2001) & $1.06(94)$ & $22.14 \pm 7.34$ \\
\hline
\end{tabular}

Explanation and abbreviations: * - macropterous females; pre-OP - pre-oviposition period. The length of pre-OP of females is the period in days from the day they were transfered from the field to the laboratory, to the day on which they first laid eggs. The numbers in the brackets are the numbers of females in the samples that were tested.

of this bug might play an important role in the spread of its macropterous genotype to new areas.

The aim of the present paper was therefore to show that pre-diapause mating and the overwintering of fertilized females is not an unusual phenomenon in $P$. apterus populations, and that seasonal dynamics and the life-cycle phenology of this flightless wing-polymorphic species is more flexible than hitherto supposed.

\section{MATERIAL AND METHODS}

\section{Sampling of insects}

Adults of $P$. apterus were collected from populations located at České Budějovice - Stromovka (Czech Republic, South Bohemia $48^{\circ} 59^{\prime} \mathrm{N}, 14^{\circ} 28^{\prime} \mathrm{E}, 400 \mathrm{~m}$ a.s.l.) and the towns of Křemže $\left(48^{\circ} 54^{\prime} \mathrm{N}, 14^{\circ} 18^{\prime} \mathrm{E}, 521 \mathrm{~m}\right.$ a.s.l.), Jistebnice $\left(49^{\circ} 29^{\prime} \mathrm{N}\right.$, $14^{\circ} 31^{\prime} \mathrm{E}, 578 \mathrm{~m}$ a.s.1.) and Chelčice $\left(49^{\circ} 7^{\prime} \mathrm{N}, 14^{\circ} 9^{\prime} \mathrm{E}, 457 \mathrm{~m}\right.$ a.s.1.), which are $20-50 \mathrm{~km}$ from České Budějovice. The bugs were collected either during diapause but before overwintering (in August-November) or after completion of diapause and overwintering (during January-February) in years 2000-2007. Large samples of adult females (at most 208 individuals) were collected at random from each of the populations. The fieldcollected specimens were immediately transported to the Institute of Entomology in České Budějovice. The bugs were classified as brachypters or macropters, based on the absence or the presence of a wing membrane (Socha \& Sula, 1996) and adult females of each wing morph kept separately. The samples included mainly specimens of the brachypterous morph, which is dominant in South-Bohemian populations of this bug (Socha, 1993; Socha \& Šula, 1996).

\section{Analysis of life-cycle parameters}

The field-collected females of $P$. apterus were transported (ca. 1-3 h) in plastic bottles with perforated caps to the laboratory and immediately transferred to a long-day $(18 \mathrm{~L}: 6 \mathrm{D})$ photoperiod and a constant temperature of $26 \pm 1^{\circ} \mathrm{C}$. The bugs were kept individually in Petri dishes (6 cm diameter) and supplied with linden seeds (Tilia cordata Miller) and water ad libitum. The water was supplied in small glass tubes plugged with cotton wool. Egg laying and mortality of these females were checked daily. The 1st egg batch laid by each of these females was transferred to Petri dishes $(6 \mathrm{~cm}$ diameter) provisioned with linden seeds and water, and whether the eggs hatched determined.
The following parameters were recorded: (1) reproductive vs. diapausing status of females; (2) the average length of preoviposition period (pre-OP), i.e. the time in days that elapsed between collecting the adult females and their laying the 1st batch of eggs; (3) the percentage (\%) of diapausing females that were fertilized before overwintering, and (4) the percentage (\%) of overwintering fertilized females. The reproductive vs. diapausing status of individual females was determined based on the length of pre-OP. Females that did not oviposit within 14 days of being transfered from the field to a long-day (18L : 6D) photoperiod and a temperature of $26 \pm 1{ }^{\circ} \mathrm{C}$ in the laboratory were considered to be in diapause (Socha \& Hodková, 1994). Females whose eggs hatched were considered as fertilized. Diapausing fertilized females vs. overwintering fertilized females, which had completed diapause, were distinguished by the length of their pre-OP, which is considerably shorter in the latter females (Socha \& Šula, 1996). The length of pre-OP of overwintered post-diapausing females, i.e. those that completed hibernal diapause as late as early February (Hodek, 1971), decreases to ca. 8 days, which is similar to that recorded for reproductively active (non-diapausing) females.

\section{RESULTS}

\section{Percentage of diapausing fertilized females in field populations of $P$. apterus}

The percentage of adult females that were fertilized in samples of $P$. apterus, collected from populations in different places during the months August-November of the years 2000-2005, was determined. Results of the fertilization tests are summarized in Table 1.

The percentage of diapausing fertilized females in 11 samples collected from field populations collected between August and November was relatively low and varied from 1.06 to $14.9 \%$ depending on the month and year of collection. All the females tested had already entered reproductive diapause, since the lengths of pre-OP of these females were longer than 14 days, which is the criterion for the intensification or maintenance of diapause in this species (Socha \& Hodková, 1994). The length of pre-OP of the females tested varied from 19.43 to 33.33 days, depending on the month and year of collection. As in a previous study, such females were classified 
TABLE 2. The percentage of overwintering fertilized brachypterous females in the field-collected samples of different populations of $P$. apterus and the average lengths of their pre-oviposition periods (years 2001-2007).

\begin{tabular}{lccc}
\hline Population & $\begin{array}{c}\text { Date of collection } \\
\text { Month and day (Year) }\end{array}$ & $\begin{array}{c}\text { Percentage (\%) of overwintering fertilized females } \\
\text { No. of females tested (n) }\end{array}$ & $\begin{array}{c}\text { Length of pre-OP } \\
\text { (days) } \pm \text { S.D. }\end{array}$ \\
\hline Č. Budějovice & January 9 (2001) & $3.54(113)$ & $10.41 \pm 2.78$ \\
Č. Budějovice & January 10 (2002) & $0.0(40)$ & $13.75 \pm 6.54$ \\
Č. Budějovice & January 24 (2002) & $3.41(88)$ & $12.07 \pm 3.32$ \\
Č. Budějovice & January 9 (2007) & $2.40(208)$ & $12.56 \pm 6.20$ \\
Chelčice & February 5 (2002) & $1.05(95)$ & $11.95 \pm 5.99$ \\
Křemže & February 5 (2002) & $5.32(94)$ & $10.06 \pm 4.02$ \\
Křemže & February 15 (2001) & $7.23(83)$ & $8.61 \pm 3.07$ \\
Č. Budějovice & February 29 (2006) & $6.42(187)$ & $9.83 \pm 2.52$ \\
Č. Budějovice & February 7 (2001) & $1.41(71)$ & $10.85 \pm 2.64$ \\
\hline
\end{tabular}

Explanation and abbreviations: pre-OP - pre-oviposition period. The length of pre-OP of females is the period in days from the day they were transfered from the field to the laboratory, to the day on which they first laid eggs. The numbers in the brackets are the numbers of females in the samples that were tested.

as in diapause. The diapausing females whose pre-OPs were longer than 14 days and they laid fertilized eggs were classified as diapausing fertilized females. Results indicate that at least a small percentage of the females in all the populations studied were fertilized, which indicates that they must have mated before entering diapause, most likely during the second half of July or exceptionally at the start of August. This indicates that mating between pre-diapause adults occurs in this insect.

\section{Percentage of overwintering fertilized females in field populations of $P$. apterus}

The results for females collected from populations at different places in January and February in 2000-2007 are summarized in Table 2.

The percentage of overwintering fertilized females in 9 samples collected in the field in January and February was as low as that recorded in the field the previous August-November. The percentage of overwintering fertilized females ranged from 1.05 to $7.23 \%$ and the average pre-OP of these females varied from 8.61 to 13.75 days, depending on the month and year they were collected. Since the average lengths of the pre-OP of these females were shorter than 14 days, they were classified as overwintered post-diapausing females. Because they were no longer sensitive to the diapause-inducing short-day photoperiod and had already completed their reproductive diapause, the length of their pre-OP was almost as short as that of reproductively active females. Females whose pre-OPs were shorter than 14 days and which laid fertile eggs were classified as overwintering fertilized females. Females that laid sterile eggs and had pre-OPs shorter than 14 days were classified as overwintering non-fertilized females. These results indicate that a small percentage of the females collected in the field had mated and were fertilized before the onset of diapause, survived the cold conditions and successfully overwintered.

\section{DISCUSSION}

\section{Pre-diapause mating and the overwintering of fertilized females in insects}

The results indicate that a small percentage of $P$. apterus females of the 1 st generation in the field in temperate regions mate prior to entering diapause and can successfully overwinter with their ovaries at the previtellogenic stage of development and viable sperm in their spermathecae. As these females are fertilized they can disperse from their place of birth and produce offspring without mating again. The results of the present study indicate that mating prior to diapause and the overwintering of fertilized females is not an unusual phenomenon in populations of $P$. apterus in temperate regions.

According to Merle (1969) this bug has two generations per year in the south of France. Adults of the 1st generation reproduce and then die whereas those of the 2nd generation enter diapause and successfully overwinter. Whether any of the adult females of the second generations mate, lay eggs and then enter diapause and survive over-winter is unknown, but this seems unlikely. Previously Socha \& Šla (1992) reported that P. apterus might also complete two generations per a year in northern temperate regions. In addition, the results of the present study indicate that a fraction of diapausing and overwintering females in temperate regions could be fertilized. It cannot be excluded, however, that this type of life cycle prevails or occurs more frequently at southern localities. Laboratory mating tests also provide evidence indicating that females of $P$. apterus that have mated can overwinter. Almost 30 and $50 \%$ of the pre-diapause macropterous and brachypterous females tested, respectively, were fertilized by reproductively active brachypterous males (Socha, unpubl. data). The present results indicate that the life-cycle of $P$. apterus is more flexible than hitherto supposed.

The percentage of overwintering fertilized females of $P$. apterus most probably varies between years, depending not only on the environmental conditions, but also on the physiological status of the fertilized females 
and the length of their adult life. It cannot be excluded that the viability of sperm and its storage in the spermatheca of reproductively active, pre-diapausing and diapausing fertilized females, and also the ratio between these types of females varies between years depending on the temperature and differences in microclimatic conditions. The percentage of overwintering fertilized females of $P$. apterus in individual years might also depend on different survival rates of these females during hibernation. In many taxa of insects the number of sperm stored by females is lower than that transferred by males during copulation (Eady, 1994; Bloch Qazi et al., 1996; Bernasconi et al., 2002) and is influenced by various factors (Simmons, 2001). Provided that there is a positive relationship between the length of adult life, sperm viability and temperature, then the incidence of pre-diapause mating and the percentage of overwintering fertilized females of $P$. apterus could be theoretically higher in populations originating from warmer localities and southern countries. However, if the non-fertilized females suffer less mortality than fertilized females after exposure to low temperature during winter, then the opposite result is expected. Irrespective of the possible differences in the sperm viability and which of above-mentioned alternatives is valid, sperm storage by overwintering females of $P$. apterus has not been previously documented. Thus, the present study for the first time demonstrates that fertilized females of this bug can survive a long period of cold conditions with fertile sperm stored in their spermathecae. The longevity of the sperm in the bursa copulatrix of overwintering fertilized females of $P$. apterus was found to be at least 7-8 months. Overwintered females of this bug can lay eggs that in some cases were fertilized by the sperm of matings that occurred prior to overwintering. Thus, a certain percentage of overwintering genomes may be those of adult females and the sperm from matings from the previous summer. This is the first record of prediapause mating and overwintering of fertilized females for this bug. This observation accords well with the knowledge that in some insect species semen is stored in the spermatheca of females and remains alive from a few days in certain flies up to a few years in some ants and the honeybee (Apis mellifera L.) (Taber \& Blum, 1960; Parker, 1970). Storage of sperm by females is an important aspect of the reproduction of several species, because it enables mating and oviposition to occur at widely separated intervals (Hatch, 1983; Briskie \& Montgomerie, 1993). Overwintering of fertilized females is reported to occur e.g. in some coccinellids (Hodek \& Landa, 1971; Hodek \& Ceryngier, 2000), the grasshopper Anacridium aegyptium L. (Pener, 1992), fruit fly Drosophila pseudoobscura Frolova and Astaurov (Collet \& Jarman, 2001), most mosquitoes, such as Anopheles, Culex and Culiseta from cool-temperate regions (Mouchet et al., 1969; Sulaiman \& Service, 1983), the spider mite Tetranychus urticae Koch (So \& Takafuji, 1991) and the cyclopoid copepod, Cyclops strenuus Fischer (Naess \& Nilssen, 1991).

\section{The possible role of overwintering fertilized females in the life-cycle of $P$. apterus}

Brachypterous and macropterous females of $P$. apterus that mate before they enter diapause and overwinter can produce progeny without mating again the following spring. It is possible that pre-diapause mating and fertilization of females is adaptive, because sperm storage by females means they can disperse, lay fertilized eggs and successfully colonize habitats where there are no males. It is probable, that pre-diapause mating occurs not only in phenotypically macropterous females but also in phenotypically "brachypterized" females with a macropterous genotype, which develop when larvae of the homozygous macropterous strain are exposed to low temperature and/or photoperiods shorter than 16 h (Honěk, 1987; Socha, unpubl. data). Fertilization of $P$. apterus females before overwintering and dispersal to new habitats the following spring might be an important aspect of the life cycle of this bug, which enables them to colonize new areas, even in the absence of males. This newly described aspect of the life cycle of $P$. apterus appears to be especially important for macropterous adults that have a greater walking and dispersal capability (Socha \& Zemek, 2000b, 2003) and readily leave their natal sites and disperse to new areas. It could play an important role in the spread of the macropterous trait to new areas and the flow of the macropterous genes between populations of $P$. apterus. This suggestion accords well with the finding that almost $30 \%$ of the macropterous females of the oriental chinch bug, Cavelerius saccharivorus Okajima, are inseminated just before emigration (Fujisaki, 1992) and the knowledge that patterns of gene flow are strongly influenced by the reproductive and dispersal strategies of animals (Olivieri et al., 1995; Paradis, 1998). Thus, the pre-diapause mating strategy of some heterozygous or homozygous females of $P$. apterus with macropterous genes (either in macropterous or "brachypterized" phenotypic form) before dispersal might be an important aspect of the life cycle of this bug and account for the low incidence of non-functional macroptery in recent populations of this flightless wing-polymorphic insect.

ACKNOWLEDGEMENTS. This study was supported by grant No. P501/10/1215 from the Czech Science Foundation (DK) and the Institute of Entomology project No. Z50070508 funded by the Academy of Sciences of the Czech Republic. The author thanks D. Rienesslová for technical assistance.

\section{REFERENCES}

Bernasconi G., Hellriegel B., Heyland A. \& Ward P.I. 2002: Sperm survival in the female reproductive tract in the fly Scatophaga stercoraria (L.). J. Insect Physiol. 48: 197-203.

Bloch Qazi M.C., Herbeck J.T. \& Lewis S.M. 1996: Mechanisms of sperm transfer and storage in the red flour beetle (Coleoptera: Tenebrionidae). Ann. Entomol. Soc. Am. 89: 892-897.

Briskie J.V. \& Montgomerie R. 1993: Patterns of sperm storage in relation to sperm competition in passerine birds. Condor 95: 442-454.

Collet J.I. \& Jarman M.G. 2001: Adult female Drosophila pseudoobscura survive and carry fertile sperm through long 
periods in the cold: Populations are unlikely to suffer substantial bottlenecks in overwintering. Evolution 55: 840-845.

EADY P.E. 1994: Sperm transfer and storage in relation to sperm competition in Callosobruchus maculatus. Behav. Ecol. Sociobiol. 35: 123-129

FUJISAKI K. 1992: A male fitness advantage to wing reduction in the oriental chinch bug, Cavelerius saccharivorus Okajima (Heteroptera, Lygaeidae). Res. Popul. Ecol. 34: 173-183.

НАтсн S.A. 1983: Mechanism and ecological significance of sperm storage in the Northern fulmar with reference to its occurrence in order birds. Auk 100: 593-600.

HoDEK I. 1968: Diapause in females of Pyrrhocoris apterus L. (Heteroptera). Acta Entomol. Bohemoslov. 65: 422-435.

Hodek I. 1971: Termination of adult diapause in Pyrrhocoris apterus (Heteroptera: Pyrrhocoridae) in the field. Entomol. Exp. Appl. 14: 212-222.

HODEK I. 1988: Photoperiodic response and reproductive activity in Pyrrhocoris apterus L. (Heteroptera) in relation to diapause development. Zool. Jb. Physiol. 92: 57-70.

Hodek I. \& Cerryngier P. 2000: Sexual activity in Coccinelidae (Coleoptera): a review. Eur. J. Entomol. 97: 449-456.

Hodek I. \& LANDA V. 1971: Anatomical and histological changes during dormancy in two Coccinelidae. Entomophaga 16: $239-251$.

HoNĚK A. 1974: Wing polymorphism in Pyrrhocoris apterus (L.) (Heteroptera: Pyrrhocoridae): influence of photoperiod. Věst. Čs. Spol. Zool. 38: 241-242.

HoNĚK A. 1976: The regulation of wing polymorphism in natural populations of Pyrrhocoris apterus (Heteroptera, Pyrrhocoridae). Zool. Jb. Syst. 103: 547-570.

HoNĚK A. 1981: Temperature and wing polymorphism in natural populations of Pyrrhocoris apterus L. (Heteroptera, Pyrrhocoridae). Zool. Jb. Syst. 108: 487-501.

HoNĚK A. 1986a: Enhancement of fecundity in Pyrrhocoris apterus under alternating natural conditions (Heteroptera, Pyrrhocoridae). Acta Entomol. Bohemoslov. 83: 411-417.

HoNĚK A. 1986b: Inheritance of wing form in Pyrrhocoris apterus. J. Hered. 77: 465-467.

HoNĚK A. 1987: Wing polymorphism in Pyrrhocoris apterus (Heteroptera, Pyrrhocoridae): penetrance of recessive macropterous homozygotes and duration of larval development. Genetica 73: 211-215.

KošŤÁL V. \& ŠIMEK P. 2000: Overwintering strategy in Pyrrhocoris apterus (Heteroptera): the relations between life-cycle, chill tolerance and physiological adjustements. J. Insect Physiol. 46: 1321-1329.

MerLe J. 1969: Anatomie des appareils genitaux mâle et femelle et fonctionnement ovarien de Pyrrhocoris apterus (L.) Hemiptera, Pyrrhocoridae). Acta Entomol. Bohemoslov. 66: 275-288.

Mouchet J., Reegeau J. \& Chippaux A. 1969: Hibernation de Culex modestus Ficalbi (Diptera, Culicidae) en Camargue. Cah. ORSTOM Ser. Entomol. Med. Parasitol. 7: 35.

NAess T. \& NiLssen J.P. 1991: Diapausing fertilized adults. A new pattern of copepod life cycle. Oecologia 86: 368-371.

Olivieri I., Michalakis Y. \& Gouyon P.H. 1995: Metapopulation genetics and the evolution of dispersal. Am. Nat. 146: 202-228.

PARADIS E. 1998: Interactions between spatial and temporal scales in the evolution of dispersal rate. Evol. Ecol. 12: 235-244.

PARKER G.A. 1970: Sperm competition and its evolutionary consequences in the insects. Biol. Rev. 45: 525-567.
Pener M.P. 1992: Environmental cues, endocrine factors, and reproductive diapause in male insects. Chronobiol. Internat. 9: $102-113$.

Pouvreau A. 1963: Cycle biologique et interprétation de l'arrêt de développement chez Pyrrhocoris apterus L. (Hemiptera, Gymnocerate, Pyrrhocoridae). Bull. Soc. Zool. France 1963: 180-196.

Schulze P. 1913: Bemerkungen zur Lebensgeschichte von Pyrrhocoris apterus L. Dt. Entomol. Z. 1919: 159-161.

SCHWOERBEL W. 1956: Beobachtungen und Untersuchungen zur Biologie einiger einheimischer Wanzen: Beobachtungen an einer Population von Pyrrhocoris apterus L. Zool. Jb. 84: 329-354.

Simmons L.W. 2001: Sperm Competition and its Evolutionary Consequences in the Insects. Princeton University Press, Princeton and Oxford, $448 \mathrm{pp}$.

So P.M. \& TAKAfuJ A. 1991: Coexistence of Tetranychus urticae (Acraina: Tetranychidae) with different capacities for diapause: comparative life-history traits. Oecologia 87: 146-151.

Socha R. 1993: Pyrrhocoris apterus (Heteroptera) - an experimental model species: a review. Eur. J. Entomol. 90: 241-286.

Socha R. 2001: Latitudinal gradient in response of wing polymorphism to photoperiod in a flightless bug, Pyrrhocoris apterus (L.) (Heteroptera: Pyrrhocoridae). Eur. J. Entomol. 98: $167-169$.

SochA R. 2004: Decreased mating propensity of macropterous morph in a flightless wing-polymorphic insect, Pyrrhocoris apterus (L.) (Heteroptera). Eur. J. Entomol. 101: 539-545.

SocHA R. 2006: Endocrine control of wing morph-related difference in mating success and accessory gland size in male firebugs. Anim. Behav. 71: 1273-1281.

Socha R. \& Hodková M. 1994: Selection for non-diapause in the heteropteran Pyrrhocoris apterus. Hereditas 120: 81-85.

Socha R. \& Šula J. 1992: Voltinism and seasonal changes in haemolymph protein pattern of Pyrrhocoris apterus (Heteroptera: Pyrrhocoridae) in relation to diapause. Physiol. Entomol. 17: 370-376.

Socha R. \& ŠULA J. 1996: Differences in haemolymph proteins in relation to diapause and wing dimorphism in Pyrrhocoris apterus (Heteroptera: Pyrrhocoridae). J. Comp. Physiol. (B) 166: 382-387.

Socha R. \& Zемек R. 2000a: Wing movement behavior in longand short-winged morphs of flightless bug Pyrrhocoris apterus L. (Heteroptera: Pyrrhocoridae). J. Insect Behav. 13: 741-750.

Socha R. \& ZemeK R. 2000b: Locomotor activity in adult Pyrrhocoris apterus (Heteroptera) in relation to sex, physiological status and wing dimorphism. Physiol. Entomol. 25: 383-389.

SochA R. \& ZEMEK R. 2003: Wing morph-related differences in the walking pattern and dispersal in a flightless bug, Pyrrhocoris apterus (L.) (Heteroptera). Oikos 100: 35-43.

Sulaiman S. \& Service M.W. 1983: Studies on hibernating populations of the mosquito Culex pipiens L. in southern and northern England. J. Nat. Hist. 17: 849-857.

TABER S. \& Blum M.S. 1960: The preservation of honeybee semen. Science 131: 1734-1735.

Tischler W. 1959: Zur Biologie der Feuerwanze Pyrrhocoris apterus L. Zool. Anz. 163: 392-396.

Received May 10, 2010; revised and accepted July 7, 2010 